\title{
Computational studies on 1,2,4-Triazolium-based salts as energetic materials
}

\author{
RAKHI SINGH, HARI JI SINGH* and S K SENGUPTA \\ Department of Chemistry, DDU Gorakhpur University, Gorakhpur 273009, India \\ e-mail: hjschem50@gmail.com
}

MS received 16 October 2014; revised 27 February 2015; accepted 27 February 2015

\begin{abstract}
The results of the computational studies performed on 1,2,4-triazolium cation-based salts designed by pairing it with energetic nitro-substituted 5- membered $\mathrm{N}$-heterocyclic anions such as 5-nitrotetrazolate, 3,5-dinitrotriazolate, and 2,4,5 trinitroimidazolate are reported. Condensed phase heats of formation of the designed ionic salts and their thermodynamic and energetic properties have also been calculated. The results show that these salts are potential energetic materials and possess high positive heats of formation. The detonation velocity, $\mathrm{D}$, and detonation pressure, $\mathrm{P}$, have been calculated using the Kamlet-Jacobs equation and found to be $7-8 \mathrm{~km} / \mathrm{s}$ and $25-29 \mathrm{GPa}$, respectively. These values fall in the range of the criteria to designate them as high-energy-density materials. Nucleus independent chemical shift (NICS) studies performed on the designed molecules show that these salts are stable in nature.
\end{abstract}

Keywords. DFT; energetic materials; lattice energy; NICS.

\section{Introduction}

Energetic materials store relatively large amount of energy in a compact and readily deliverable form. In recent years, syntheses of new heterocyclic-based energetic, low-melting salts have drawn significant attention. ${ }^{1-4}$ These materials possess an added advantage over nonionic molecules in the sense that they exhibit very low vapour pressure that significantly eliminates the risk of exposure through inhalation. On account of the Coulombic forces that encourage the formation of ordered and dense lattice structures in molecular assemblies, ionic compounds often possess higher density than their atomically similar non-ionic analogues. High-density compounds show better explosive characteristics because the two most important parameters the detonation pressure and the detonation velocity both depend on initial loading density and, in fact, the detonation pressure, $\mathrm{P}$, varies linearly to the square of the density.

The presence of $\mathrm{N}-\mathrm{N}$ and $\mathrm{C}-\mathrm{N}$ bonds in nitrogenrich heterocycles results in high heats of formation and high densities. Their low content of carbon and hydrogen also gives rise to a good oxygen balance that is needed for an efficient combustion. The decomposition products of these CHNO-type energetic compounds predominantly consist of $\mathrm{CO}_{2}, \mathrm{H}_{2} \mathrm{O}$, and $\mathrm{N}_{2}$, which make them very promising candidates to be used as eco-friendly energetic materials. ${ }^{2}$ Five-membered

\footnotetext{
*For correspondence
}

nitrogen-containing rings such as imidazole, triazole, and tetrazole are a natural framework for designing energetic materials and their performance can be optimized and improved by substituting hydrogen atoms with nitro, dinitramide, azido, and other explosophores. ${ }^{5}$

Energetic salts based on $\mathrm{C}-\mathrm{N}$ hetero-aromatic rings with high nitrogen content are of interest for high energy research. There is a growing interest in triazolebased compounds as high-energy propellants. Triazoles are five-membered aromatic heterocycles that contain three nitrogen atoms. A schematic representation of 1,2,4-triazole is shown in figure 1.

A large number of ionic compounds that contain a triazole moiety have been synthesized that are found to be energetic materials. ${ }^{6-9}$ Incorporating different explosophores into 1,2,4-triazolium cation has been envisaged to be a plausible way of improving its energetic properties. For example, when endothermic moieties, such as azido and nitro groups, are introduced into azoles, the enthalpy of formation of 1,2,4-triazole and its salts is increased by $335-377 \mathrm{~kJ} / \mathrm{mol} .{ }^{10}$ Furthermore, the study performed by Meot-Ner et al. ${ }^{11}$ has shown that among the two available $\sigma$ protonation sites $\mathrm{N} 2$ and N4 in 1,2,4-triazole, the protonation at N4 is favoured by 55 $\mathrm{kJ} / \mathrm{mol}$ than that at $\mathrm{N} 2$ position.

Recently, a great deal of interest has been shown for the synthesis of 1,2,4-triazolium-based salts from the viewpoint of being used as high energetic materials. ${ }^{3,10,12-15}$ In this study, we had made an effort to design a suitable 1,2,4-triazolium cation with increased 


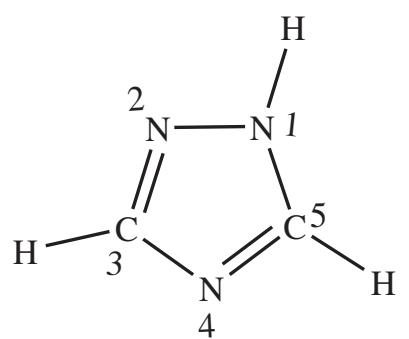

Figure 1. 1,2,4-Triazole.

basicity so that it could be coupled with energetic anions to make high-energy salts. In this context, we placed methyl groups at N1 and N4 positions of the 1,2,4-triazole ring knowing the fact that the $-\mathrm{CH}_{3}$ group has an electron-donating character. In doing so, the electron density at the ring would increase and ultimately increase its basicity. Alternatively, the energy content of the cation could be increased by incorporating $-\mathrm{NO}_{2}$ and $-\mathrm{N}_{3}$ groups as explosophores. Thus, two cations, namely, 1,4-dimethyl-3-azido-5-nitro-1,2,4-triazolium (C1) and 1,4-dimethyl-3,5-dinitro-1,2,4-triazolium(C2), are designed. These nitro and azido group substituted cations are paired with three energetic anions, namely, 5-nitro-tetrazolate (A1), 3,5-dinitro-1,2,4-triazolate (A2) and 2,4,5-trinitroimidazolate (A3). Thus, a total of six high energy salts (I-VI) have been designed and studied in detail in the present investigation.

Volume-based thermodynamic calculations have been performed to obtain the density and heat of formation (HOF). Lattice energies and condensed phase heats of formation have been determined. Detonation properties such as detonation pressure $(\mathrm{P})$ and detonation velocity (D) are also calculated in order to see the potentialities of the designed compounds. The stability of the ring system has also been assessed with the NuclearIndependent Chemical Shifts (NICS) ${ }^{16,17}$ study using the Gauge Independent Atomic Orbital (GIAO) method. ${ }^{18}$

\section{Computational Details}

\subsection{Electronic Structure Studies}

Electronic structure calculations were performed using Gaussian 09 suite of programs and the methods implemented therein. ${ }^{19}$ The geometry optimization and frequency calculation for all the species involved during the present study were carried out based on density functional theory (DFT) using B3LYP functional with $6-311++\mathrm{G}(\mathrm{d}, \mathrm{p})$ basis set. DFT with a modest basis set has been proved to be a reliable method for predicting the thermodynamic and subsequently the explosive characteristics of many organic and nitrosubstituted polyaromatic high-energy materials. ${ }^{20-22} 6$ $311++\mathrm{G}(\mathrm{d}, \mathrm{p})$ is considerably a large basis set that includes diffused and polarized functions that take into account the characteristics associated with ionic species having heavy atoms such as N. Optimizations were performed without any symmetry constraint using the default convergence criteria provided in the Gaussian 09 program. All the optimized structures were subjected to frequency calculation to ensure that the structures belonged to true local minima on their respective potential energy surface (PES) by confirming that all the frequencies were real and positive.

\subsection{Heat of Formation}

The heat of formation is often treated as an indication of energy content of the material. From the viewpoint of practical applications, performance parameters and thermodynamic properties of such materials need to be determined under condensed phase conditions. However, only empirical methods have been adopted to calculate the heat of formation of condensed phase compounds in many of the studies dealing with high-energetic compounds. In this study, we employed a combination of density functional data and empirical methods to

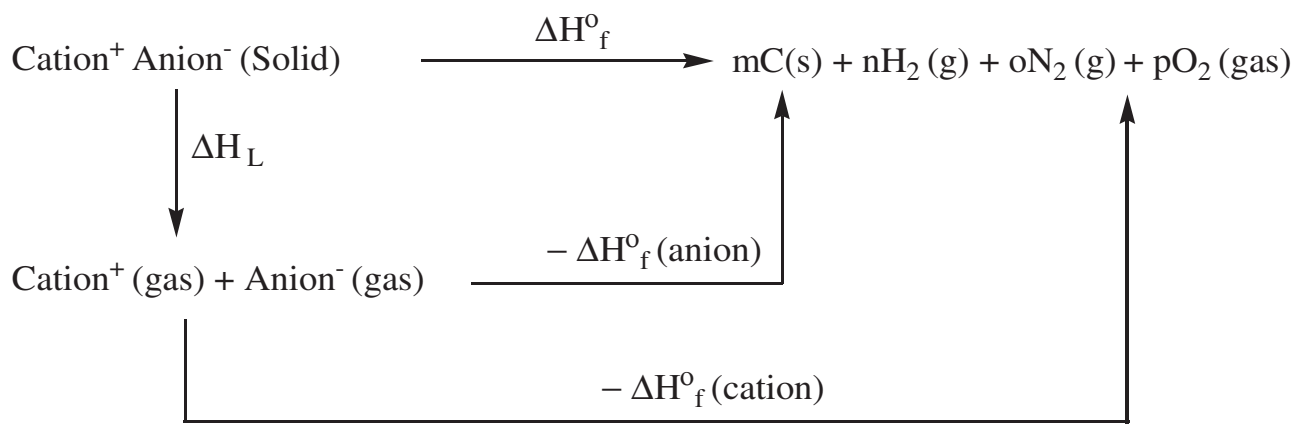

Figure 2. Thermodynamic cycle for the determination of heat of formation of an ionic salt in the condensed phase. 
determine the heat of formation of the designed species in the condensed phase. Based on the Born-Haber thermodynamic cycle as shown in figure 2, the heat of formation of an ionic salt can be written as

$$
\begin{aligned}
& \Delta_{\mathrm{f}} \mathrm{H}^{0} \text { (ionic salt, 298K) }=\Delta_{\mathrm{f}} \mathrm{H}^{0} \text { (cation, 298K) } \\
& \quad+\Delta_{\mathrm{f}} \mathrm{H}^{0} \text { (anion, 298K) }-\Delta \mathrm{H}_{\mathrm{L}}
\end{aligned}
$$

where, $\Delta \mathrm{H}_{\mathrm{L}}$ represents the lattice energy of the salt. In order to use equation (1) for the calculation of $\Delta_{\mathrm{f}} \mathrm{H}^{0}$ of the designed salts, the heats of formation of cations, anions, and $\Delta \mathrm{H}_{\mathrm{L}}$ of the salt must be known. We used the isodesmic method ${ }^{23}$ to calculate the heats of formation of the designed salts. In this method, the target molecule is broken into a set of molecules containing the same component bonds as were present in the parent molecule. The number and types of bonds in the reactant and product side are conserved. The requisite isodesmic reactions designed for the calculation of heats of formation of the cations, $\mathbf{C 1}$ and $\mathbf{C 2}$, are shown in scheme 1. In designing these isodesmic reactions, due care was taken to keep the delocalised 1,2,4-triazolium cation skeleton intact. ${ }^{24,25}$ For an isodesmic reaction, the heat of reaction $\Delta \mathrm{H}_{298 \mathrm{~K}}$ can be written as

$$
\Delta \mathrm{H}_{298 \mathrm{~K}}=\sum \Delta_{\mathrm{f}} \mathrm{H}_{\mathrm{P}}-\sum \Delta_{\mathrm{f}} \mathrm{H}_{\mathrm{R}}
$$

where $\Delta_{\mathrm{f}} \mathrm{H}_{\mathrm{R}}$ and $\Delta_{\mathrm{f}} \mathrm{H}_{\mathrm{P}}$ are the heats of formation of reactants and products at $298 \mathrm{~K}$.

The main difficulty in evaluating $\Delta \mathrm{H}_{298 \mathrm{~K}}$ using equation (2) is that the experimental heats of formation of all the product and reactant species involved in the isodesmic reactions devised in scheme 1 are not known. The experimental $\Delta_{\mathrm{f}} \mathrm{H}^{0}$ values of a few of the species involved in the isodesmic reactions mentioned above are taken from the NIST database, ${ }^{26}$ and these are listed here in $\mathrm{kJ} / \mathrm{mol}$ as $\mathrm{CH}_{4}(-74.40), \mathrm{NH}_{3}(-46.10)$,
$\mathrm{CH}_{3} \mathrm{NO}_{2}(-80.80)$ and $\mathrm{CH}_{3} \mathrm{NH}_{2}(-22.50)$. The heats of formation of the remaining four species, namely, the triazolium and substituted triazolium cations $(\mathbf{C 1}$ and C2) and $\mathrm{CH}_{3} \mathrm{~N}_{3}$, are not known. These were evaluated using the atomization method and the required data were obtained by performing calculations at a considerably higher level of theory using the G2 method. Thus, $\Delta \mathrm{H}_{298 \mathrm{~K}}$ of the isodesmic reactions were calculated using ab-initio data in the following manner:

$$
\begin{gathered}
\Delta \mathrm{H}_{298 \mathrm{~K}}=\Delta \mathrm{E}_{298 \mathrm{~K}}+\Delta(\mathrm{PV}) \\
\Delta \mathrm{H}_{298 \mathrm{~K}}=\Delta \mathrm{E}_{0}+\Delta \mathrm{ZPE}+\Delta \mathrm{H}_{\mathrm{T}}+\Delta \mathrm{nRT}
\end{gathered}
$$

where $\triangle E_{0}$ and $\triangle Z P E$ are the change in the total electronic energies and zero-point energies of products and reactants at $0 \mathrm{~K}$, and $\Delta H_{\mathrm{T}}$ is the enthalpy change in bringing the reactant and product species from 0 to 298 $\mathrm{K}$. The $\Delta(P V)$ term in equation (3) is the $P V$ work term and is equal to $\triangle n R T$ for the reactions assumed to be occurring under ideal conditions. For isodesmic reactions considered in scheme 1 , the value of $\Delta \mathrm{n}$ is equal to zero and, therefore, equation (3) takes the following form:

$$
\Delta \mathrm{H}_{298 \mathrm{~K}}=\Delta \mathrm{E}_{0}+\Delta \mathrm{ZPE}+\Delta \mathrm{H}_{\mathrm{T}}
$$

The values of the three parameters on the right-hand side of equation (5) were obtained from the ab-initio calculations performed at the G2 compound level of theory. Thus, $\Delta H_{298 \mathrm{~K}}$ can be determined with the help of equation (5). Subsequently, with the help of equation (2), the heats of formation of the designed cations $\mathbf{C 1}$ and $\mathbf{C 2}$ were evaluated.

\subsection{Lattice energy $\left(\Delta H_{L}\right)$}

There is no direct $a b$ initio method to calculate the lattice energy $\left(\Delta H_{\mathrm{L}}\right)$ of a salt. We employed here the<smiles>Cn1nc(N)[n+](C)c1[N+](=O)[O-]</smiles>

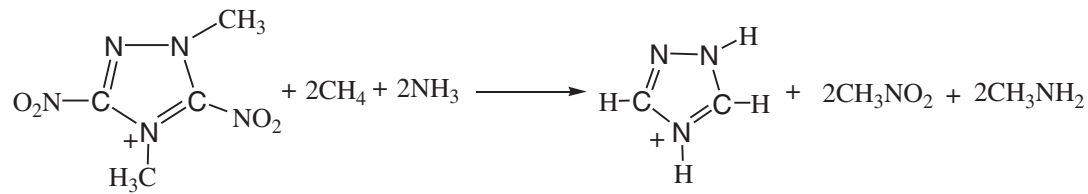

1,4-dimethyl-3,5-dinitro-

1,2,4-triazolium cation $(\mathbf{C} 2)$

1,2,4-triazolium cation

Scheme 1. Isodesmic reactions designed for $\mathrm{C} 1$ and $\mathrm{C} 2$ cations. 
method developed by Jenkins et $a .^{27}$ as given by the following expression:

$$
\Delta \mathrm{H}_{\mathrm{L}}=\mathrm{U}_{\mathrm{POT}}+\left[p\left(n_{M} / 2-2\right)+q\left(n_{X} / 2-2\right)\right] \mathrm{RT}
$$

where $n_{M}$ and $n_{X}$ depend on the nature of ions constituting the salt $M_{\mathrm{p}} X_{\mathrm{q}}$. These are equal to 3 for monoatomic ions and 5 and 6 for linear and non-linear polyatomic ions, respectively. In the case of a 1:1 salt, the values of $p$ and $q$ are equal to 1 and, therefore, equation (6) takes the following form:

$$
\Delta \mathrm{H}_{\mathrm{L}}=\mathrm{U}_{\mathrm{POT}}+2 \mathrm{RT}
$$

The lattice potential energy $\left(U_{\mathrm{POT}}\right)$ is determined by an equation given by Jenkins et al. ${ }^{27}$ as given below:

$$
\mathrm{U}_{\mathrm{POT}}=\gamma\left[\left(\rho_{\mathrm{m}}\right) /\left(\mathrm{M}_{\mathrm{m}}\right)\right]^{1 / 3}+\delta
$$

where $\gamma$ and $\delta$ were listed as $1981.2 \mathrm{~kJ} \mathrm{~mol}^{-1} \mathrm{~cm}$ and $103.8 \mathrm{~kJ} \mathrm{~mol}^{-1}$. The density $\left(\rho_{\mathrm{m}}\right)$ used in the above expression can simply be determined by the expression given as

$$
\rho_{\mathrm{m}} / \mathrm{g} \mathrm{cm}^{-3}=\left(\mathrm{M}_{\mathrm{m}} / \mathrm{g}\right) /\left(\mathrm{V}_{\mathrm{m}} / \mathrm{cm}^{3}\right)
$$

where, the molecular volume, $V_{\mathrm{m}}$, needed for the calculation of the density was calculated using volumebased thermodynamics (VBT) ${ }^{28}$ method that has been found to be a reliable method for the estimation of lattice energy and the heat of formation (HOF) of the salts in the condensed phase. ${ }^{29,30}$ For an ionic salt $M_{\mathrm{p}} X_{\mathrm{q}}$, it is taken as the sum of volumes of cation and anion contained in its formula unit and can be written as

$$
\mathrm{V}_{\mathrm{m}}=\mathrm{pV}_{\mathrm{M}}^{+}+\mathrm{qV}_{\mathrm{X}}^{-}
$$

The ionic volumes $V_{\mathrm{M}}^{+}$and $V_{\mathrm{X}}^{-}$were estimated using the Monte Carlo method based on 0.001 electron/bohr ${ }^{3}$ density space as implemented in Gaussian 09 suite of programs. In the present study, 100 single point calculations were performed at B3LYP/6-311++G(d,p) level and an average volume of the respective ion was determined. This approach has successfully been employed for the estimation of molecular volumes in the case of high-nitrogen compounds. ${ }^{31}$ To gauge the reliability of the estimated molecular volumes obtained using the Monte Carlo method, the volumes of the designed ionic salts were also estimated by the Hoffmann's elemental volume method ${ }^{32}$ given by the following equation:

$$
\mathrm{V}_{\mathrm{m}} \text { (ionic salt) }=\mathrm{aV}(\mathrm{C})+\mathrm{bV}(\mathrm{H})+\mathrm{cV}(\mathrm{N})+\mathrm{dV}(\mathrm{O})
$$

where $a, b, c$ and $d$ are the number of $\mathrm{C}, \mathrm{H}, \mathrm{N}$, and $\mathrm{O}$ atoms present in the formula unit of the ionic salt and $V$ 's are their corresponding volumes. The values of the latter in the unit of $\mathrm{nm}^{3}$ were taken from Ref. ${ }^{33}$ and are listed as $\mathrm{C}=0.0138, \mathrm{H}=0.00508, \mathrm{~N}=0.0118, \mathrm{O}=$ 0.01139 .

\subsection{Detonation velocity and detonation pressure}

Detonation velocity (D) and detonation pressure (P) for the designed compounds were calculated using the Kamlet-Jacobs equations ${ }^{34}$ as given by the following expressions:

$$
\begin{gathered}
\mathrm{D}=1.01\left(\mathrm{~N} \mathrm{M}^{1 / 2} \mathrm{Q}^{1 / 2}\right)^{1 / 2}(1+1.30 \rho) \\
\mathrm{P}=1.558 \rho^{2} \mathrm{~N} \mathrm{M}^{1 / 2} \mathrm{Q}^{1 / 2}
\end{gathered}
$$

where $\mathrm{D}$ is the detonation velocity $(\mathrm{km} / \mathrm{s}) ; \mathrm{P}$, the detonation pressure $(\mathrm{GPa}) ; \mathrm{N}$, number of moles of gaseous products formed per gram of explosive; $\mathrm{M}$, average molecular weight of gaseous product formed during detonation; $\mathbf{Q}$, heat of detonation ( $\mathrm{cal} / \mathrm{g})$; and $\rho$, the density of explosive $\left(\mathrm{g} / \mathrm{cm}^{3}\right)$. The density $(\rho)$ was determined from the molecular mass $\left(\mathrm{M}_{\mathrm{w}}\right)$ divided by the molecular volume calculated by the Monte Carlo method, as discussed earlier. To determine the values of $\mathrm{N}, \mathrm{M}$, and $\mathrm{Q}$, idealized detonation reaction for each salt is designed in terms of maximum exothermal principle based on the assumption that in the case of detonation of $\mathrm{C}-\mathrm{H}-\mathrm{N}-\mathrm{O}$ compounds, all the $\mathrm{N}$ atoms turn into $\mathrm{N}_{2}$ gas, the $\mathrm{O}$ atoms react with $\mathrm{H}$ atoms to form $\mathrm{H}_{2} \mathrm{O}$, and then forms $\mathrm{CO}_{2}$ with $\mathrm{C}$ atoms. If the number of $\mathrm{O}$ atoms is more than what is needed to oxidise $\mathrm{C}$ and $\mathrm{H}$ atoms, the redundant $\mathrm{O}$ atoms will convert into $\mathrm{O}_{2}$ gas. This is the situation if the compound is over-oxidised. By contrast, if the content of $\mathrm{O}$ atoms is not sufficient enough to satisfy the full oxidation of $\mathrm{C}$ and $\mathrm{H}$ atoms, that is, in the case of under-oxidised compounds, the remaining $\mathrm{H}$ will convert into hydrogen gas and the $\mathrm{C}$ will exist as $\mathrm{C}$ solid. Thus, it is assumed that the reaction products of a $\mathrm{C}-\mathrm{H}-\mathrm{N}-\mathrm{O}$ compound would consist of $\mathrm{H}_{2} \mathrm{O}, \mathrm{N}_{2}, \mathrm{CO}_{2}$, and either $\mathrm{C}$ (graphite) or $\mathrm{O}_{2}$ as determined by the oxygen balance of the unreacted explosive. Thus, the values of $N$ and $M$ were calculated. The heat of detonation, $\mathrm{Q}$, was evaluated as

$$
Q=\frac{-\left[\Delta_{f} H\left(\text { detonation products }-\Delta_{f} H(\text { explosive })\right]\right.}{\text { Formula weight of explosive }}
$$

\subsection{Oxygen Balance (OB\%)}

The oxygen balance $(\mathrm{OB} \%)$ represents the percentage of oxygen required for complete conversion of carbon to carbon dioxide and hydrogen to water. The compound may have negative or positive oxygen balance showing them to be under- or over-oxidized, respectively. In general, the explosive characteristics such as the sensitivity, strength, and brisance of an explosive 
are somewhat good when OB\% is zero or near zero. Oxygen balance is used to indicate the degree to which a compound can be oxidised and to classify energetic materials as either oxygen rich or oxygen deficient. It is calculated

$$
O B \%=1600 \frac{n_{\mathrm{O}}-2 n_{C}-0.5 n_{\mathrm{H}}}{\text { Molecular Weight }}
$$

where $n_{O}, n_{H}$ and $n_{C}$ are the number of $\mathrm{C}, \mathrm{H}$ and $\mathrm{O}$ atoms present in the molecular formula of the compounds, respectively.

\subsection{Nucleus-independent chemical shift}

Nucleus-independent chemical shift (NICS) study ${ }^{35,36}$ has been considered to be an important criterion to predict the stability of a compound in reference to its aromaticity. The aromatic character of the ring is reflected by its high negative value (diatropic ring current), whereas the positive value (paratropic current) corresponds to anti-aromaticity. It has been observed that NICS(1) value measured at $1 \AA$ above and below the plane of the ring (which reflects the $\pi$ effect) is a better representation of the ring current and thus the aromaticity of the cation. In the present study, NICS was performed at the centre of the ring and $1 \AA$ above/below the ring for isolated cations and ionic salts using the GIAO approach.

\section{Results and Discussion}

\subsection{Density}

Density of a high-energy material is an important parameter that determines the brisance of the material.
In fact, it is directly related to the detonation pressure as given by equation (13) that shows its strong dependence as it varies directly with the square of the initial loading density $(\rho)$. The densities are calculated from the molar volumes determined from two independent methods: (1) the ab initio method based on the Monte Carlo approach and taken as an statistical average determined on 0.001 electron/bohr ${ }^{3}$ density space and (2) utilizing the Hoffman's elemental volume method. ${ }^{32}$ Monte Carlo calculations were performed on the optimized structures of the species involved during the present calculations. These structures obtained at B3LYP/6$311++\mathrm{G}(\mathrm{d}, \mathrm{p})$ are shown in figures $3-5$. The volumes of the ionic salts calculated using equations (10) and (11) are recorded in table 1 . Both methods yield consistent values. This gives us the confidence to use the $a b$ initio data to calculate the densities of the designed ionic salts. The volumes calculated by $a b$ initio method for the designed cations, $\mathbf{C 1}$ and $\mathbf{C 2}$, are found to be 119.1 and $117.9 \mathrm{~cm}^{3} / \mathrm{mol}$. A slightly lower value in the case of $\mathbf{C 2}$ (1,4-dimethyl-3,5-dinitro-1,2,4-triazole) cation may be assigned to the fact that one more nitro group is attached at $\mathrm{C} 3$ position in the triazole moiety, which is adjacent to the methyl group present at the N4 position. This can result in a more pronounced hydrogen bonded interaction, leading to a compact ion and thus lowering its volume. The data recorded in table 1 also show that the addition of nitro groups on the anions also resulted in an increase in the ionic size as is the case with A1-A3. The anion $\mathbf{A} \mathbf{1}$ that possesses only one nitro group attached to the tetrazole ring has a volume of $59.1 \mathrm{~cm}^{3} / \mathrm{mol}$, while $\mathbf{A 2}$ and $\mathbf{A} \mathbf{3}$ that consist of two and third nitro groups attached to triazole and imidazole rings have considerably higher volumes of 82.0 and $105.4 \mathrm{~cm}^{3} / \mathrm{mol}$, respectively. It is noteworthy that the calculated volumes of

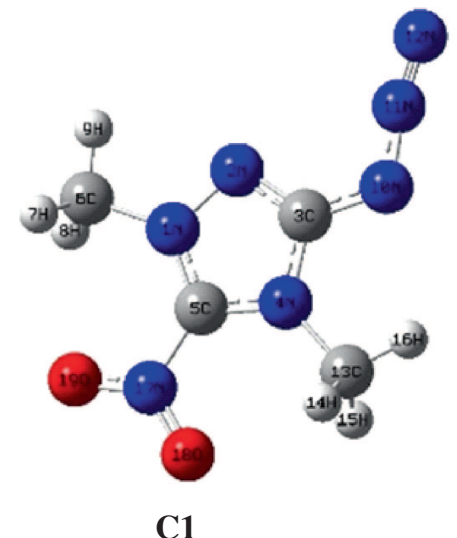

1,4-dimethyl-3-azido-5-nitro-1,2,4triazolium

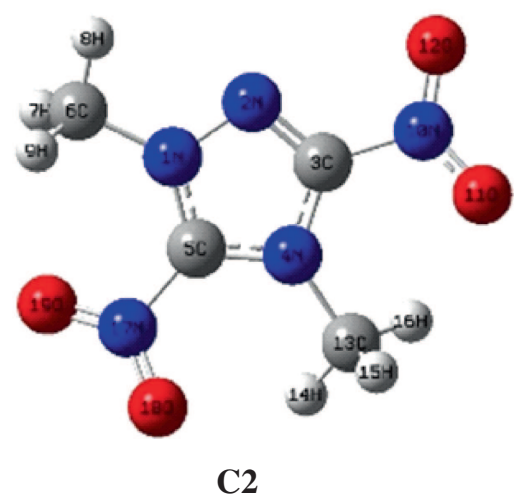

1,4-dimethyl-3,5-dinitro-1,2,4-triazolium

Figure 3. Optimized structures of substituted 1,2,4-triazolium cations. 


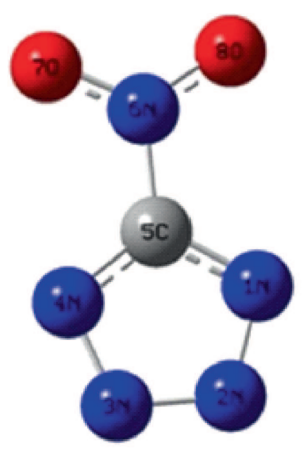

A1

5-nitro-tetrazolate

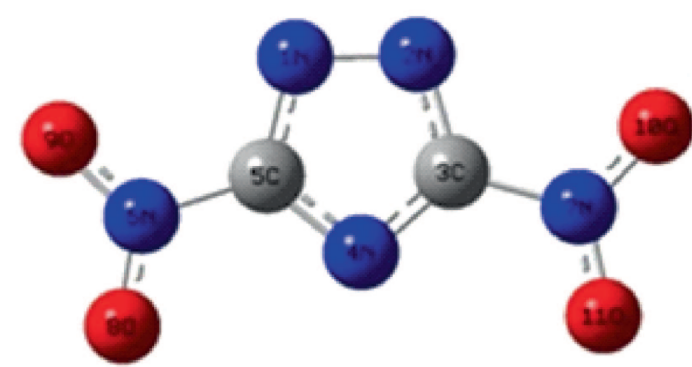

A2
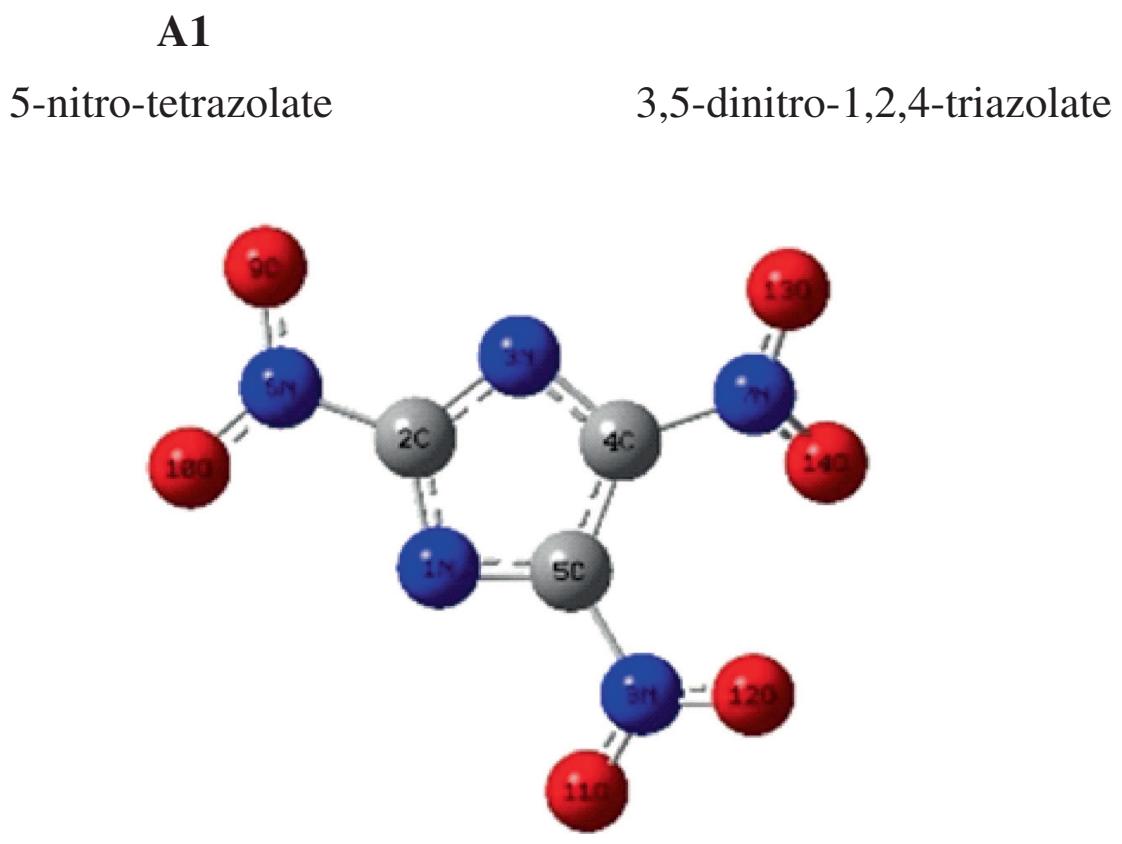

A3

\section{2,4,5-trinitro-imidazolate}

Figure 4. Optimized structures of various anions.

imidazole, trizole, and tetrazole consisting of 2, 3, and 4 $\mathrm{N}$ atoms in the ring moiety using the method employed during the present study yielded the values of 59.1, 49.1 and $43.1 \mathrm{~cm}^{3} / \mathrm{mol}$, respectively. This clearly shows that the increase in the number of nitrogen atoms in the ring moiety makes the ring more compact. This may be due to an increase in the number of lone pair electrons available with the nitrogen atoms that take part effectively in the delocalization of the ring. However, this decrease in volume is not very significant. The results further show that it is the nitro group attached to the ring moiety that is responsible for the increase in the volume of the anions. The same trend is observed in the case of the ionic salts formed with cations $\mathbf{C 1}$ and C2. A slight lower value of the salts of cation $\mathbf{C 2}$ may be because the ionic volume of $\mathbf{C 2}$ is about $1 \mathrm{~cm}^{3} / \mathrm{mol}$ lower than that of $\mathbf{C 1}$. The results also show that all the designed compounds have an average density of
$1.75 \mathrm{~g} / \mathrm{cm}^{3}$, which is considerably higher than the most commercially used explosive TNT $\left(1.64 \mathrm{~g} / \mathrm{cm}^{3}\right)^{37}$ and closer to the powerful explosive RDX $\left(1.80 \mathrm{~g} / \mathrm{cm}^{3}\right){ }^{37}$ These results show that salts in which the cation is substituted by two nitro groups such as the case with $\mathbf{C 2}$ possessing a higher density. This may be due to intramolecular hydrogen bonding because the two nitro groups are vicinal to the methyl group present at the ring. This additional interaction may be responsible for the closed packing, leading to the lowering of the ionic volumes.

\subsection{Heat of Formation}

High positive heat of formation is the desired criterion for the material to be highly energetic. The requisite $a b$ initio data needed for the calculation of the heats of formation of cations (C1 and $\mathbf{C 2}$ ) and anions (A1-A3) 

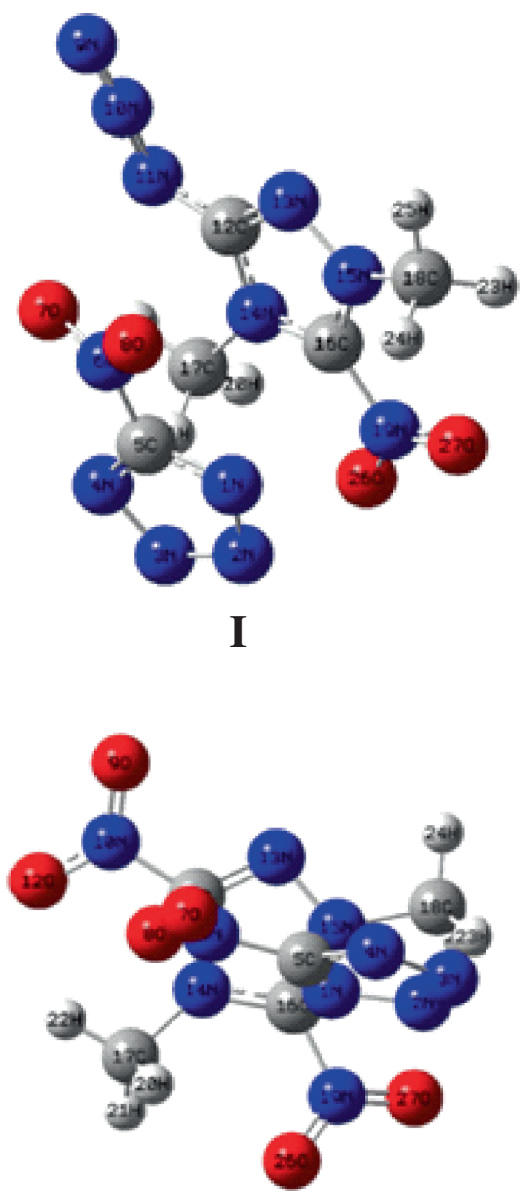

IV

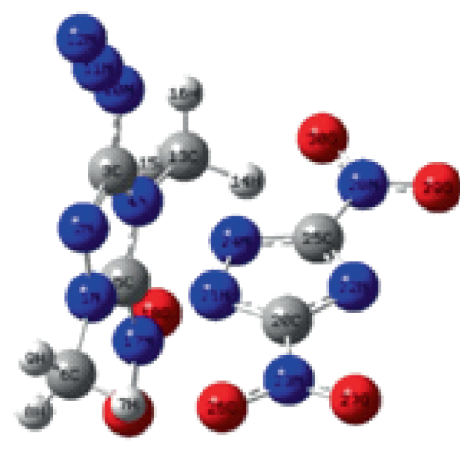

II

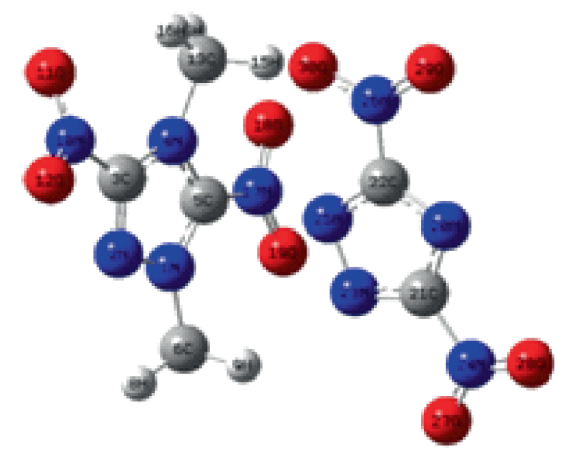

V

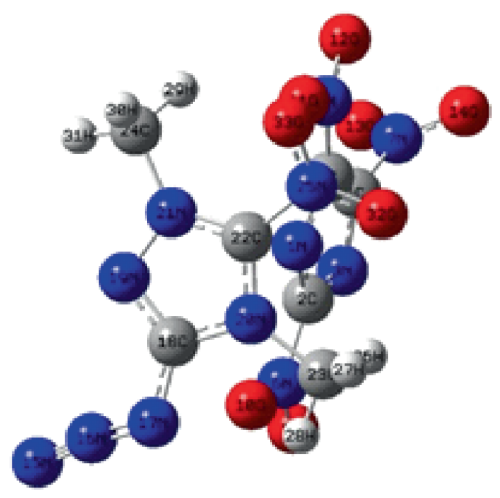

III

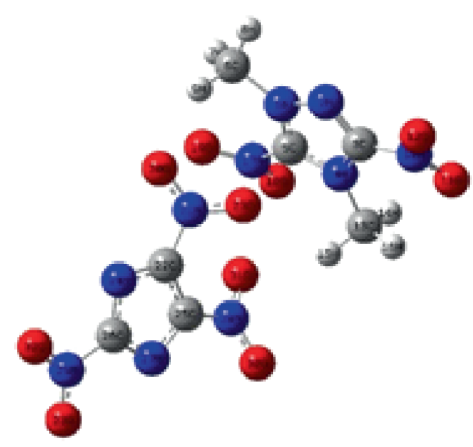

VI

Figure 5. Structures of ionic salts optimized at DFT(B3LYP)/6-311++G(d,p).

Table 1. Volumes of cations, anions, and the ionic salts calculated using the Monte Carlo and Hoffmann's elemental volume (HEV) methods.

\begin{tabular}{|c|c|c|c|c|c|}
\hline Cation & Anion & Salt & $\frac{V_{\mathrm{m}}\left(\mathrm{cm}^{3} / \mathrm{m}\right.}{\text { Monte Carlo }}$ & $\frac{\mathrm{nol})}{\mathrm{HEV}}$ & $\begin{array}{c}\text { Density }(\rho) \\
\left(\mathrm{g} / \mathrm{cm}^{3}\right)\end{array}$ \\
\hline $\mathrm{C} 1$ & - & - & 119.1 & 119.4 & - \\
\hline $\mathrm{C} 2$ & - & - & 117.9 & 118.9 & - \\
\hline- & A1 & - & 59.1 & 59.7 & - \\
\hline- & $\mathrm{A} 2$ & - & 82.0 & 82.6 & - \\
\hline \multirow[t]{3}{*}{-} & A3 & - & 105.4 & 105.4 & - \\
\hline & & $\mathrm{I}(\mathrm{C} 1-\mathrm{A} 1)$ & 178.2 & 179.1 & 1.67 \\
\hline & & II (C1-A2) & 201.1 & 202.0 & 1.70 \\
\hline- & - & III (C1-A3) & 224.5 & 224.8 & 1.71 \\
\hline- & - & IV $(\mathrm{C} 2-\mathrm{A} 1)$ & 177.0 & 178.6 & 1.70 \\
\hline- & - & $\mathrm{V}(\mathrm{C} 2-\mathrm{A} 2)$ & 199.9 & 201.5 & 1.73 \\
\hline \multirow[t]{3}{*}{-} & - & VI (C2-A3) & 223.3 & 224.4 & 1.74 \\
\hline & & TNT & & & $1.64^{\mathrm{a}}$ \\
\hline & & RDX & & & $1.80^{\mathrm{a}}$ \\
\hline
\end{tabular}

${ }^{\mathrm{a}}$ Ref. $^{37}$

C1 and C2 are 1,4-dimethyl-3-azido-5-nitro-1,2,4-triazolium and 1,4-dimethyl-3,5-dinitro-1,2,4-triazolium cations and A1, A2, and A3 are 5-nitrotetrazolate 3,5- dinitro-1,2,4triazolate and 2,4,5-trinitroimidazolate anions, respectively. were obtained at G2 level of calculation, and these are recorded in table 2 . The condensed phase heats of formation of $1 \mathrm{H}$-imidazole, $1 \mathrm{H}$-1,2,4-trizole and $1 \mathrm{H}$ tetrazole are reported to be $58.5,109$ and $237.2 \mathrm{~kJ} / \mathrm{mol}$, respectively. ${ }^{38}$ The high positive heats of formation of these azoles are attributed to the presence of energetic $\mathrm{N}-\mathrm{N}$ and $\mathrm{C}-\mathrm{N}$ bonds in the ring moiety. This trend is maintained in the designed ionic salts as reflected by the data recorded in table 2 . The results show that in spite of adding three nitro groups on the imidazolate anion that contains two nitrogen atoms in the ring, the heats of formation of the corresponding salts (C1-A3) and (C2-A3) are lower than their counterparts made with triazolate and tetrazolate anions that contains three and four nitrogen atoms in the ring moiety, respectively. The data listed in table 2 also include the lattice energies of the salts which lie in the range of $430-470 \mathrm{~kJ} / \mathrm{mol}$. This is comparable to the value of $400-500 \mathrm{~kJ} / \mathrm{mol}$ obtained previously for a $1: 1$ salt. ${ }^{39}$ It is observed that the heat of formation of the salt increases as the number of nitrogen atoms in anions increases. In cation $\mathbf{C 1}$, the presence of azido $\left(-\mathrm{N}_{3}\right)$ group increases its heat of formation, 
Table 2. Heats of formation of cations, anions, and their salts along with the lattice energy. All values are given in $\mathrm{kJ} / \mathrm{mol}$.

\begin{tabular}{lcccc}
\hline Ionic salts & $\Delta_{\mathrm{f}} \mathrm{H}^{0}$ (anion) & $\Delta_{\mathrm{f}} \mathrm{H}^{0}$ (cation) & $\Delta \mathrm{H}_{\mathrm{L}}$ & $\Delta_{\mathrm{f}} \mathrm{H}^{0}$ (ionic salts) \\
\hline I (C1-A1) & 114.5 & 1200.1 & 460.5 & 854.0 \\
II (C1-A2) & -42.6 & 1200.1 & 445.5 & 712.0 \\
III (C1-A3) & -157.1 & 1200.1 & 430.9 & 612.1 \\
IV (C2-A1) & 114.5 & 961.6 & 459.4 & 616.6 \\
V (C2-A2) & -42.6 & 961.6 & 445.6 & 473.3 \\
VI (C2-A3) & -157.1 & 961.6 & 434.8 & 369.7 \\
\hline
\end{tabular}

Table 3. NICS(1) values for the cations in the designed ionic salts.

\begin{tabular}{lc}
\hline SALTS & NICS(1) \\
\hline C1(Isolated) & -9.18 \\
I (C1-A1) & -10.14 \\
II (C1-A2) & -10.35 \\
III (C1-A3) & -11.07 \\
C2 (Isolated) & -9.11 \\
IV (C2-A1) & -9.91 \\
V (C2-A2) & -10.37 \\
VI (C2-A3) & -11.17 \\
\hline
\end{tabular}

whereas in the case of $\mathbf{C 2}$ presence of two nitrogroups in the ring increases the electron delocalisation through resonance effect that would provide stability to the cation that may be responsible for decreasing its heat of formation.

\subsection{Nucleus-independent chemical shift}

An NICS study is performed to predict the stability of compounds through aromaticity. NICS(1) values of cations $\mathrm{C} 1$ and $\mathrm{C} 2$ in isolation and in the designed ionic pairs are given in table 3 . Results show that the NICS(1) values of both cations ( $\mathrm{C} 1$ and $\mathrm{C} 2$ ) increase with increase in the number of nitro groups attached with the heterocyclic ring and it is maximum $(\sim-11.0)$ for trinitroimidazolate anion. High negative NICS values show pronounced aromaticity of the ring and hence a better stability of the ion pair due to delocalisation of $\Pi$ electrons. This increase may also be due to the large size of this anion, which is a diffused charged species and could have a strong influence on the delocalisation of the corresponding cations. This is also supported by the thermodynamic data recorded in table 2, which shows that the salts formed with $\mathbf{A 3}$ anion possessed lower positive heats of formation, leading to a more stable salt.
Table 4. Detonation properties of the ionic salts.

\begin{tabular}{lccccc}
\hline Salt & OB\% & $\begin{array}{c}\mathrm{Q} \\
(\mathrm{cal} / \mathrm{g})\end{array}$ & $\begin{array}{c}\text { Density }(\rho) \\
\left(\mathrm{g} / \mathrm{cm}^{3}\right)\end{array}$ & $\begin{array}{c}\mathrm{D} \\
(\mathrm{Km} / \mathrm{s})\end{array}$ & $\begin{array}{c}\mathrm{P} \\
(\mathrm{GPa})\end{array}$ \\
\hline I (C1-A1) & -48.32 & 1424.56 & 1.67 & 7.79 & 25.75 \\
II (C1-A2) & -42.35 & 1425.20 & 1.70 & 7.87 & 26.68 \\
III (C1-A3) & -74.61 & 1437.04 & 1.71 & 8.00 & 27.57 \\
IV (C2-A1) & -37.08 & 1527.60 & 1.70 & 8.13 & 28.53 \\
V (C2-A2) & -32.36 & 1505.89 & 1.73 & 8.20 & 29.22 \\
VI(C2-A3) & -65.64 & 1514.76 & 1.74 & 8.20 & 29.28 \\
TNT & -74.00 & $1090.82^{\mathrm{c}}$ & $1.64^{\mathrm{a}}$ & $6.93^{\mathrm{a}}$ & $21.00^{\mathrm{b}}$ \\
RDX & -21.60 & $1510.99^{\mathrm{c}}$ & $1.80^{\mathrm{a}}$ & $8.75^{\mathrm{a}}$ & $34.10^{\mathrm{b}}$ \\
\hline
\end{tabular}

${ }^{\mathrm{a}}$ Experimental values reported in Ref. ${ }^{37}$.

${ }^{\mathrm{b}}$ Experimental values reported in Ref. ${ }^{40}$.

${ }^{\mathrm{c}}$ Experimental values reported in Ref. ${ }^{41}$.

\subsection{Energetic Properties}

Detonation pressure and detonation velocity are two important properties of an energetic compounds to guess its potential applications. Table 4 shows the predicted heats of detonation $(\mathrm{Q})$, detonation velocities $(\mathrm{D})$, and detonation pressure $(\mathrm{P})$ for the designed salts along with commonly used explosives TNT and RDX. The calculated values of $\mathrm{Q}, \mathrm{D}$ and $\mathrm{P}$ show that the detonation velocities and detonation pressures of the designed salts are in the range of $7-8 \mathrm{~km} / \mathrm{s}$ and $25-29 \mathrm{GPa}$, respectively. The largest value of $\mathrm{D}$ and $\mathrm{P}$ has been predicted for salts $\mathbf{V}$ and VI. The OB\% values of all the designed salts are also listed in table 4. Results show that all the designed salts are under-oxidized. The results show that the designed salts can be used as potential high-energetic materials.

\section{Conclusions}

Heat of formation, lattice enthalpies, and lattice potential energies were determined using G2-level calculations and volume-based thermodynamic calculations (VBT) methods. Detonation properties were determined 
using the Kamlet-Jacobs equations. It has been found that nitro and azido-substituted 1,2,4-triazolium cationbased salts have higher densities and possess better detonation properties. The heat of formation of azido substituted salts is higher as compared to the nitro substituted salts. The calculated energetic properties indicate that the $-\mathrm{NO}_{2}$ and the $-\mathrm{N}_{3}$ groups are the effective structural units for enhancing the detonation performance of the substituted triazolium cations. The present study reveals that these salts may be considered as potential candidates for high energy materials.

\section{Acknowledgements}

One of the authors (RS) is thankful to UGC, New Delhi, for providing financial support under its DSA (BSR) programme. Thanks are also due to the Head of the Chemistry Department for allowing Authors to avail the necessary computational facilities of the department. The authors are thankful to a reviewer for very relevant and supportive suggestions to improve the quality of the manuscript.

\section{References}

1. Singh R P, Verma R D, Meshari D T and Shreeve J M 2006 Angew. Chem. Int. Ed. 453584

2. Tao G H, Gao Y, Parrish D A and Shreeve J M $2010 \mathrm{~J}$. Mater. Chem. 202999

3. Xue H, Goa Y, Twamley B and Shreeve J M 2005 J. Mater. Chem. 153459

4. Xue H, Goa Y, Twamley B and Shreeve J M 2005 Chem. Mater. 17191

5. Ghule V D, Sarangapani R P, Jadhav M and Tewari S P 2011 J. Mol. Model. 171507

6. Gao H and Shreeve J M 2011 Chem. Rev. 1117377

7. Xue H, Gao H, Twamley B and Shreeve J M 2004 J. Org. Chem 691397

8. Xue H, Goa Y, Twamley B and Shreeve J M 2005 Inorg. Chem. 445068

9. Schmidt M W, Gordon M S and Boatz J A 2005 J. Phys. Chem. A. 1097285

10. Gutowski K E, Rogers R D and Dixon A D 2007 J. Phys. Chem. B. 1114788

11. Meot-Ner M, Liebermann J F and Del Bene J E 1986 J. Org. Chem $\mathbf{5 1} 1105$

12. Darwich C, Klapötke T M and Sabaté C M 2008 Chem. Eur. J. 145756

13. Mirzaei Y R, Xue H and Shreeve J M 2004 Inorg. Chem. 43361

14. Xue H, Arritt S W and Twamley B 2004 Inor. Chem. 43 7972

15. Darwich $\mathrm{C}$, Karagiosoff K, Klapotke $\mathrm{T}$ M and Sabate $\mathrm{C}$ M 2008 J. Allg. Chem. 63461

16. Schleyer P R, Maerker C, Dransfeld A, Jiao H and Hommes N J R E 1996 J. Am. Chem. Soc. 1186317
17. Chen Z, Wannere C S, Corminboeuf C, Puchta R and Schleyer P R 2005 Chem. Rev. 1053842

18. Wolinski K, Hilton J F and Pulay P 1990 J. Am. Chem. Soc. 1128251

19. Frisch M J, Trucks G W, Schlegel H B Scuseria G E, Robb M A, Cheeseman J R, Montgomery J A, Vreven T, Kudin K N, Burant J C, Millam J M, Iyengar S S, Tomasi J, Barone V, Mennucci B, Cossi M, Scalmani G, Rega N, Petersson G A, Nakatsuji H, Hada M, Ehara M, Toyota K, Fukuda R, Hasegawa J, Ishida M, Nakajima T, Honda Y, Kitao O, Nakai H, Klene M, Li X, Knox J E, Hratchian H P, Cross J B, Adamo C, Jaramillo J, Gomperts R, Stratmann R E, Yazyev O, Austin A J, Cammi R, Pomelli C, Ochterski J W, Ayala P Y, Morokuma K, Voth G A, Salvador P, Dannenberg J J, Zakrzewski V G, Dapprich S, Daniels A D, Strain M C, Farkas O, Malick D K, Rabuck A D, Raghavachari K, Foresman J B, Ortiz J V, Cui Q, Baboul A G, Clifford S, Cioslowski J, Stefanov B B, Liu G, Liashenko A, Piskorz P, Komaromi I, Martin R L, Fox D J, Keith T, AlLaham M A, Peng C Y, Nanayakkara A, Challacombe M, Gill P M W, Johnson B, Chen W, Wong M W, Gonzalez C and Pople J A 2010 Gaussian 09 (Wallingford CT: Gaussian, Inc.)

20. Li M, Xu H and Wu F 2014 J Mol. Model. 202204

21. Chen P C, Chieh Y C and Tzeng S C 2003 Mol. Str.: THEO. 634215

22. Singh H J, Gupta S and Sengupta S K 2014 RSC Adv 4 40534

23. Hehre W J, Ditchfield R, Radom L and Pople J A 1970 J. Amer. Chem. Soc. 924796

24. Xu X J, Xiao H M, Ju X H, Gong X D and Zhu W H 2006 J. Phys. Chem. A 1105929

25. Zhang X W, Zhu W H and Xiao H M 2010 J. Phys. Chem. A 114603

26. NIST Chemistry WebBook. Available at http://webbook. nist.gov/chemistry/ (Accessed October 3, 2014)

27. Jenkins H D B, Tudela D and Glasser L 2002 Inorg. Chem. 412364

28. Jenkins H D B and Liebman J F 2005 Inorg. Chem. 44 6359

29. Galvez-Ruiz J C, Holl G, Karaghiosoff K, Klapotke T M, Lohnwitz K, Mayer P, Noth H, Polborn K, Rohbogner C J, Suter M and Weigand J J 2005 Inorg. Chem. 444237

30. Gao H, Ye C, Winter R W, Gard G L, Sitzmann M E and Shreeve J M 2006 Eur. J. Inorg. Chem. 163221

31. Rice B M, Hare J J and Byrd E F C 2007 J Phys. Chem. A 11110874

32. Hofmann D W M 2002 Acta Crystallogr. B 58489

33. Klapotke T M, Stierstorfer J, Jenkins H D B, Eldik R V and Schmeisser M Z 2011 Anorg. Allg. Chem 6371308

34. Kamlet M J and Jacobs S J 1968 J. Chem. Phys. 4823

35. Lazzeri P 2004 Phys. Chem. Chem. Phys. 6217

36. Aihara J 2002 Chem. Phys. Lett. 36534

37. Keshavarz M H 2005 J. Haz. Mat. 12131

38. Zhang X, Zhu W, Wei T, Zhang C and Xiao H $2010 \mathrm{~J}$. Phys. Chem. 11413142

39. Gao H, Ye C, Piekarski C M and Shreeve J M 2007 J. Phys. Chem. C 11110718

40. Keshavarz M H and Pouretedal H R 2004 Therm. Acta. $\mathbf{4 1 4} 203$

41. Keshavarz M H 2007 Indian J. Eng. Mater. Sci. 14324 